\title{
PLANEJAMENTO PARA O USO PÚBLICO NO PARQUE NATURAL MUNICIPAL DA SERRA DO RELÓGIO, GUARANI, MG
}

\author{
Valéria Fernandes Rezende ${ }^{1}$ \\ Raquel Fernandes Rezende ${ }^{2}$
}

\section{Resumo}

O trabalho faz uma reflexão sobre a importância do planejamento do uso público para a prática de atividades turísticas em unidades de conservação (UCs), com vistas a assegurar que estas proporcionem sensibilização dos visitantes para a conservação da natureza e, até mesmo, para mudanças de hábitos que contribuirão para o menor comprometimento possível dos recursos naturais. Será apresentado um breve relato da experiência de elaboração do Plano de Uso Público contido no Plano de Manejo do Parque Natural Municipal da Serra do Relógio (PNMSR) Município de Guarani, Estado de Minas Gerias. Neste sentido, foi possível concluir que pensar, criar e implementar planos, programas, projetos e ações, como instrumentos de planejamento e gestão para o uso público em UCs, não é tarefa simples. No estudo aqui relatado isso fica evidente, tendo em vista o fato de que a UC estar em fase final de seu processo de criação e ainda não experimentar um processo de visitação formal.

Palavras-Chave: Unidades de Conservação; Parque Natural Municipal da Serra do Relógio; uso público; turismo.

\begin{abstract}
The work reflects on the importance of planning for public use for the practice of tourist activities in protected areas, in order to ensure that these provide awareness of visitors to the conservation of nature and even to change habits that contribute to the lowest possible compromise of natural resources. Will be presented a brief account of the experience of preparing the Public Use Plan contained in the Management Plan of the Natural Park of Serra do Relógio, Guarani Municipality, State of Minas Gerais, Brazil. Thus, it was concluded that thinking, creating and implementing plans, programs, projects and actions as instruments of planning and management for public use in protected areas, is no simple task. In the study reported here it is evident, in view of the fact that the protected area be in the final stages of his creative process and not yet experiencing a process of formal visitation.
\end{abstract}

Keywords: Protected Areas, Natural Park of Serra do Relógio, public use and tourism

\section{Introdução}

A preocupação com a conservação da natureza desencadeou diversas iniciativas ao longo da historia da humanidade. Entretanto, foi a partir do século XIX que a implantação de áreas que abrigavam o ambiente natural bem conservado passou a ocorrer em diferentes partes do mundo. Em paralelo à criação de tais áreas, algumas políticas voltadas para a proteção da

\footnotetext{
${ }^{1}$ Turismóloga, Consultora Ambiental. E-mail: valturrezende@ yahoo.com.br

${ }^{2}$ Geógrafa, Doutoranda Programa de Pós Graduação em Geografia da Universidade Federal Fluminense.

E-mail: quelgeorezende@yahoo.com.br
} 
natureza, reguladoras dos usos dos recursos naturais e de outras questões ambientais foram criadas e também evoluíram.

No Brasil, essa preocupação tornou-se especialmente significativa com a criação do primeiro parque brasileiro, o Parque Nacional do Itatiaia, em 1937. No decorrer dos anos muitas outras UCs foram criadas em âmbito nacional, estadual e municipal. Merece destaque a criação do Sistema Nacional de Unidades de Conservação (SNUC - Lei No 9.985 de 18 de julho de 2000) que instituiu, estabeleceu critérios e normas para as UCs, no que tange a criação, implantação e gestão destas. De acordo com a lei supracitada, unidade de conservação é definida como:

"Espaço territorial e seus recursos ambientais, incluindo as águas jurisdicionais, com características naturais relevantes, legalmente instituído pelo Poder Público, com objetivos de conservação e limites definidos, sob regime especial de administração, ao qual se aplicam garantias adequadas de proteção" (BRASIL, 2000).

Com o SNUC as unidades foram divididas em dois grupos distintos, a saber, as de Proteção Integral (onde só é permitido uso indireto dos recursos naturais - que não envolva consumo, coleta ou destruição, salvo exceções previstas na legislação) e as de Uso Sustentável (visam conciliar a exploração do ambiente com os processos ecológicos, de maneira que seja justa do ponto de vista social e viável economicamente), ambas abrigam diferentes categorias de manejo.

Dentre as unidades de proteção integral, estão os parques, objeto deste estudo que, de acordo com o SNUC, trata-se de uma área na qual a prática de turismo ecológico é prevista. Nas categorias em que tal atividade é permitida, ela deve estar de acordo com o plano de manejo da mesma, que pode ser definido como "um ciclo contínuo de consulta e tomada de decisão com base no entendimento das questões ambientais, socioeconômicas, históricas e culturais que caracterizam uma Unidade de Conservação e a região onde esta se insere" ${ }^{\text {"2 A }}$ criação de espaços territoriais especialmente protegidos, dentre estes as UCs, é considerada uma das melhores estratégias para a conservação da biodiversidade (KINKER, 2002).

O presente trabalho aborda a importância do planejamento criterioso de uma UC tendo como referência o Parque Natural Municipal da Serra do Relógio (PNMSR), localizado no município de Guarani, Zona da Mata do Estado de Minas Gerais, e em processo final de criação. Cabe mencionar que tal município integra o Circuito Turístico Caminhos Verdes de Minas, junto com outros municípios, a saber: Coronel Pacheco, Goianá, Piau, Rio Novo, São João Nepomuceno, Descoberto e Guarani. É reconhecida como uma área potencial para o desenvolvimento de atividades turísticas, desde que bem planejadas. Assim, tal planejamento tem como finalidade aliar visitação e conservação da natureza, configurando-se como um instrumento para despertar nas comunidades locais e visitantes a sensibilização para a importância e necessidade de conservação dos recursos naturais remanescentes. Neste sentido, o planejamento do uso público é fundamental, na perspectiva de que a passagem do turista

\footnotetext{
${ }^{2}$ Disponível em: < http//www.icmbio.gov.br, 2011>.
} 
pela UC vá além de um passeio, mas que seja capaz de gerar uma experiência de vivência, contemplação, interpretação, contato e sensibilização. Além da participação e envolvimento da comunidade local, tem-se a expectativa de fortalecer o sentimento de pertencimento com a área protegida. Neste sentido, o uso público compreende todas as atividades e desdobramentos referentes à utilização pelo público de uma UC, e que pode ser:

"por meio da visitação e do turismo, independentemente da motivação/atividade (contemplação, recreação, esporte, observação de aves) ou do segmento do turismo em questão (ecoturismo, turismo ecológico ou de aventura)". (RODRIUES, 2009, p. 62).

Deve ser mencionado que o PNMSR apresenta uma particularidade importante, pois o processo de sua criação vem junto com a elaboração do Plano de Manejo e, consequentemente, com o estudo do Uso Público. A área não tem visitação regularizada, não existe estrutura criada, não há trilhas estabelecidas e, portanto, quase tudo deve ser pensado para ser desenvolvido a partir da indicação do plano de manejo e de novos estudos indicados após a conclusão desse instrumento de planejamento. Frente ao exposto, será apresentado o relato da experiência de planejamento do uso público elaborado para compor o plano de manejo da UC, destacando-se a importância e necessidade de instrumentos pensados criteriosamente, para que sejam capazes de aproximar visitantes e comunidade local das questões ambientais. Neste sentido, o estudo teve a perspectiva de despertar o sentimento de pertencimento e cuidado com o local, propor edificações com a finalidade de garantir o conforto e segurança ao turista, além de viabilizar o acesso do espaço a diversos públicos.

\section{Material e métodos}

A metodologia teve como base referências da Revista Brasileira de Pesquisa em Turismo da Associação Nacional de Pesquisa e Pós Graduação em Turismo (ANPTUR). Para obtenção de dados primários foram realizados trabalhos de campo na área do parque com mapeamentos dos seus atrativos. Os dados secundários foram obtidos através de levantamentos e estudos acerca da literatura que versa sobre UCs e uso público, turismo em áreas protegidas, legislação ambiental, planejamento ambiental e turístico, interpretação e educação ambiental; consultas a documento locais (Inventário da Oferta Turística de Guarani e o estudo elaborado para a criação do Parque Natural Municipal da Serra do Relógio); consultas a trabalhos acadêmicos e a sites de órgãos oficiais como Instituto Chico Mendes de Conservação da Biodiversidade - ICMBio, Instituto Brasileiro do Meio Ambiente e Recursos Naturais Renováveis - IBAMA, Instituto Estadual de Florestas - IEF e prefeitura municipal de Guarani.

Para a coleta de dados secundários, foram feitas entrevistas semiestruturadas com informantes qualificados, para se conhecer a realidade de cada município, as práticas turísticas regionais e locais, com perguntas que buscavam nortear o planejamento turístico aliado à conservação da natureza em uma área em processo final de criação, mas sem visitação formalizada. Observações sistemáticas, conversas informais com a comunidade lideranças locais ajudaram no entendimento da dinâmica da UC. 


\section{Resultados}

A elaboração do Plano de Uso Público (PUP), contido no Plano de Manejo do PNMSR, traz reflexões acerca das alternativas capazes de modificar o momento do visitante na unidade, transformando-o da condição de um ator meramente passivo a questionador, reflexivo e sensibilizado por sua experiência turística na UC. A discussão apresentada também poderá contribuir para fortalecer o sentido de uso público e da atividade turística em UCs. Espera-se, dessa forma, consolidar posturas construtivas, agregadoras, sensibilizadoras, transformadoras e colaborativas da conservação de áreas protegidas e, também, de mudanças de atitudes cotidianas. Portanto, há que se pensar, planejar, e organizar aspectos como: ordenamento e controle da visitação, horários de visitação, atividades autorizadas, prática comercial, prática de atividades esportivas, serviços prestados ao público, estruturas e equipamentos de suporte, cobrança ou não de ingresso, comunicação ao visitante, proibições e segurança.

Cabe considerar que o PUP seguiu as orientações contidas no roteiro metodológico de planejamento do IBAMA (Instituto Brasileiro do Meio Ambiente e Recursos Naturais Renováveis), com as diretrizes institucionais para elaboração de planos de manejo disponibilizadas pelo ICMBio (2011). Tal roteiro define que para os levantamentos referentes ao uso da UC para a visitação, demandas como esta e conscientização ambiental devem ser estudadas, avaliadas, diagnosticadas, enfim, devem estar contidas no plano de manejo da UC. $\mathrm{O}$ mesmo roteiro também coloca que alguns estudos relativos às especificidades da UC em questão devem ser aprofundados. Estes levantamentos devem dar base para planos, programas, projetos e ações em que a visitação nos parques desperte no turista e na comunidade local o interesse, ou, no mínimo, que os sensibilize para a necessidade e importância de conservação da natureza.

A utilização dos atrativos dentro da UC pode apresentar características distintas, tais como: recreativas, esportivas, contemplativas, pedagógicas, artísticas, científicas, interpretativas, culturais e turísticas, preservando a harmonia destas práticas com o objetivo principal que é a conservação da natureza.

Faz-se necessário mencionar que grande parte das práticas rotuladas de turismo "ecológico", ou seja, aquele que deveria ser praticado respeitando o ambiente local e suas limitações, é, na realidade, um modelo tradicional de uso predatório, que desconsideram os impactos negativos de sua prática em UCs. Isso acontece, principalmente, quando o atrativo turístico sofre uma pressão pela demanda crescente de massificação do uso. Nesses casos configura-se um paradoxo, pois a principal fonte de renda local, ou seja, a própria UC, é ameaçada pelos seus principais beneficiários, que muitas vezes não têm uma visão clara sobre os danos causados pela excessiva exploração da unidade. A educação desses usuários e a negociação permanente sobre os limites do uso sustentável são grandes desafios para a manutenção da qualidade ambiental da área.

Torna-se significativo mencionar que é um grande desafio pensar um planejamento para o uso público de uma área ainda em processo final de criação (2011), sem visitação regularizada e nem estrutura criada. É a apresentação de dados preliminares que deverão ser 
aprofundados em estudos futuros, indicados nos programas, projetos e ações. Ao mesmo tempo é a oportunidade de iniciar o processo de visitação já com o espaço organizado, fundamentado em destinar ao visitante, por exemplo, momentos e atividades interpretativas, contemplativas, educacionais, lúdicas e de diversão que sejam capazes de sensibilizá-los para um dos objetivos primordiais da UC, a conservação da natureza local. É pertinente colocar que os levantamentos feitos na área decorrem de uma adaptação do termo de referência disponibilizado pelo ICMBio para montagem de planos de manejo de parques. Neste sentido, foi realizado o levantamento, bem como o diagnóstico dos atrativos do PNMSR, apresentados no Quadro I.

Quadro I. Atrativos em potencial do PNMSR

\begin{tabular}{|l|l|}
\hline ATRATIVO EM POTENCIAL & \multicolumn{1}{|c|}{ SITUAÇÃO ATUAL } \\
\hline Casa & $\begin{array}{l}\text { Edificação abandonada, deteriorada. } \\
\text { erosivo, irregular e com vegetação exótica } \\
\text { tomando conta do leito da trilha. }\end{array}$ \\
\hline Trilha do contorno & $\begin{array}{l}\text { Acesso dificultado pela falta de conservação } \\
\text { da trilha. }\end{array}$ \\
\hline Bosque & $\begin{array}{l}\text { Presença de muitas espécies exóticas e áreas } \\
\text { de pastagem }\end{array}$ \\
\hline Mirantes naturais & $\begin{array}{l}\text { Acesso dificultado pela falta de conservação } \\
\text { da trilha. }\end{array}$ \\
\hline Recursos hídricos & $\begin{array}{l}\text { Não há indicativos de potabilidade e } \\
\text { balneabilidade da água. }\end{array}$ \\
\hline Lagoa seca & $\begin{array}{l}\text { Acesso dificultado pela falta de conservação } \\
\text { da trilha. }\end{array}$ \\
\hline Lago & $\begin{array}{l}\text { Acesso dificultado pela falta de conservação } \\
\text { da trilha. }\end{array}$ \\
\hline Ruínas & $\begin{array}{l}\text { Acesso dificultado pela falta de conservação } \\
\text { da trilha. }\end{array}$ \\
\hline
\end{tabular}

Organização: Valéria Fernandes Rezende, 2011.

Os dois principais atrativos do parque são mostrados nas Figuras 01 e 02, porém devese considerar que, para estarem prontos para receberem os visitantes, necessitam de estudos prévios e promoção de intervenções. Estudos como capacidade de carga e monitoramento, definição do(s) período(s) de maior frequência de visitação, serviços de condução e guias, atividades educacionais e previsão dos impactos causados pela visitação pública, são imprescindíveis para garantir que a visitação ocorra sem alterar o sistema ecológico local. 


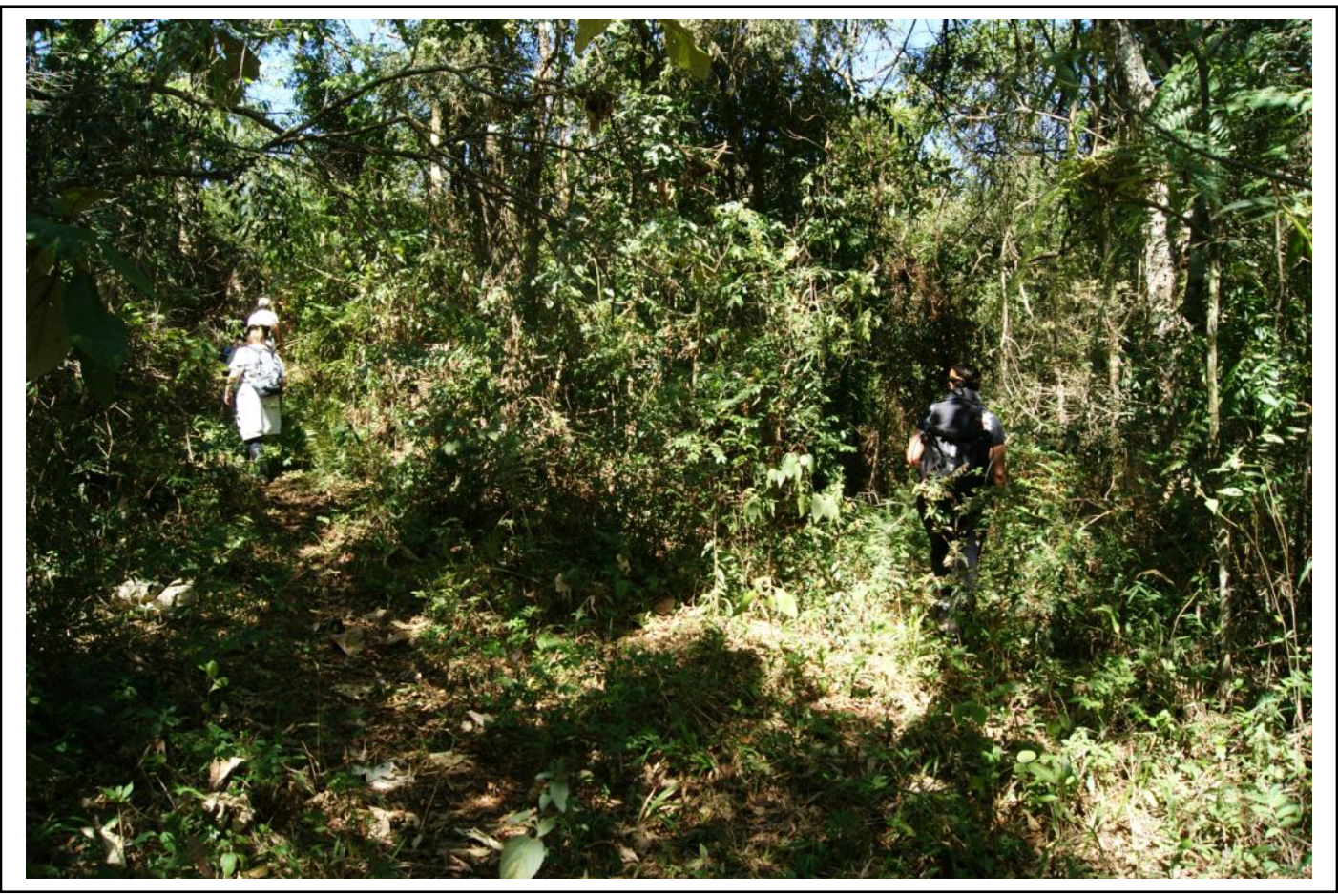

Figura 01. Trilha do Contorno no PNMSR Fonte: Biokratos, 2011.

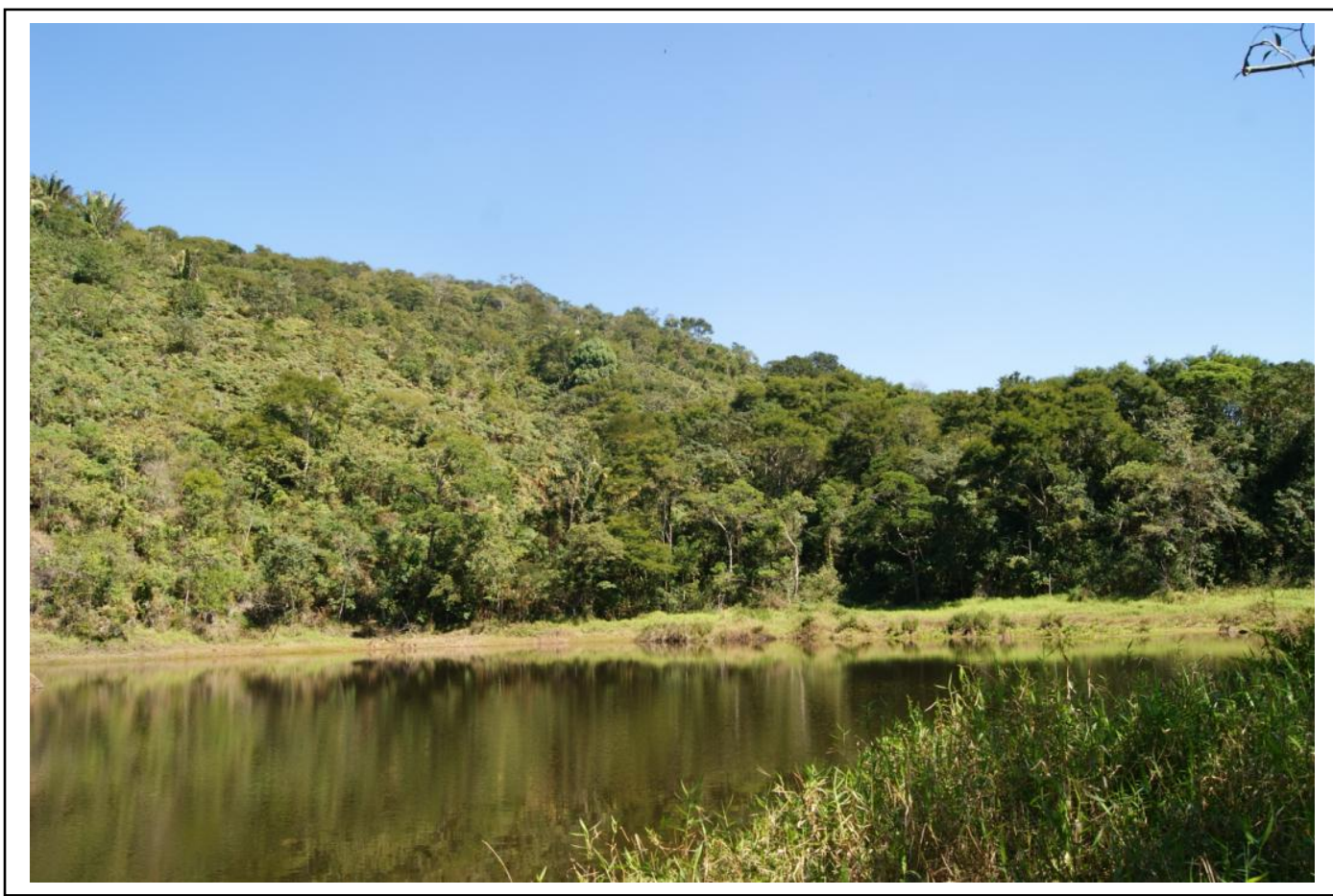

Figura 02. Atrativo turístico "lago" no PNMSR Fonte: Biokratos, 2011.

As potencialidades para visitação no PNMSR devem ser desenvolvidas mediante a criação e implantação de novas estruturas que proporcionem contato com a natureza e 
fornecer condições minimamente confortáveis, seguras e acessíveis para os turistas. As estruturas propostas são: restaurante/café; jardim sensorial; sanitários; sede administrativa; portarias e guaritas; casa do pesquisador; centro de visitantes; estacionamento e lixeiras. As intervenções devem ser feitas de acordo com as indicações do plano de manejo da unidade e com estudos futuros indicados para serem realizados, privilegiando sempre construções sustentáveis e que respeitem as premissas de uma UC.

A inserção de comunidades locais no desenvolvimento e execução de atividades de visitação pode ser estabelecida não só através da prestação de serviço por meio da condução de visitantes, mas, na participação no conselho consultivo, no planejamento e gestão das atividades, campanhas e projetos de educação ambiental, voluntariado e na criação de estruturas. Elas podem atuar nos meios de hospedagem e alimentação em propriedades próximas à UC, buscando sempre manter as tradições e práticas culturais locais que estejam em concordância com os objetivos de manejo. Deve-se também incentivar o entendimento respeitoso e recíproco entre visitantes e comunidade local, despertando na população local o sentimento de pertencimento, de respeito e sensibilização pelas causas ambientais, que serão repassados também aos turistas.

O Centro de Visitantes pode ser um espaço para a divulgação dos atrativos e atividades desenvolvidas no parque, além de informar ao visitante por meio de diversos recursos (maquetes, folheteria, vídeos e funcionários) o que o visitante encontrará na UC, os objetivos da mesma, como deve se comportar o e que é ou não permitido. Neste sentido, os folhetos poderão conter informações claras e úteis como: breve descrição sobre os atrativos; mapa de localização dos atrativos, sanitários, alimentação e outras informações; regras de conduta consciente; e informações referentes à historia da região e do Parque. Uma página na internet pode também dar informações ao visitante e à população local de tudo que acontece no PNMSR.

A sinalização deve estar por toda a área de visitação e, além do caráter informativo e orientador, deve esclarecer o que é permitido ou não dentro da UC, ter caráter educativo indicando, por exemplo, as espécies e riscos ali existentes.

É conveniente que o visitante seja estimulado a conhecer a região e interagir de maneira harmoniosa com a comunidade local. Os municípios do entorno devem também divulgar e participar sempre das atividades no PNMSR através de práticas educacionais, e culturais.

Dentre as atividades conflitantes com o objetivo da UC foi diagnosticada a prática de queimadas nas áreas agrícolas e de pecuária do entorno do parque, além da retirada de água para abastecimento destas mesmas atividades. Essas práticas podem ser suprimidas por meio da educação ambiental, sensibilização e capacitação. Assim a UC pode promover cursos para informar e capacitar, por exemplo, a prática da queimada nas áreas vizinhas.

Como já foi ressaltado, muitos dos impactos são causados pela visitação e advêm da inadequação desta atividade aos objetivos da UC. Desta maneira o estabelecimento de áreas para a visitação deve estar de acordo com a determinação do plano de manejo, respeitando-se sempre áreas para regeneração e recuperação de espécies, áreas intocáveis, áreas somente para 
pesquisa, entre outras. Planos, programas e projetos devem ser capazes de garantir que a visitação gere o menor impacto possível. Entre os programas de uso público destaca-se o monitoramento das trilhas e da visitação, relacionados à capacidade de carga, além da divulgação educativa de conduta consciente dos visitantes.

\section{Conclusões}

Após a reflexão apresentada pode-se concluir que pensar, criar e implementar planos, programas, projetos e ações como instrumentos de planejamento e gestão para o uso público em UCs, não se configura como uma tarefa fácil. Fica claro também que muito há para ser avançado no que tange ao uso público em UCs, principalmente com relação às experiências de visitação, que devem ser capazes de despertar interesses individuais e coletivos para a urgência das questões ambientais. Os avanços passam ainda pela captação de recursos e vontade de execução por parte dos gestores do que é proposto pelos instrumentos de planejamento e gestão.

Um instrumento como o plano de manejo pode ser uma ferramenta fundamental e norteadora quando criteriosamente preparada e implementada, buscando-se o estabelecimento de atividades que possam ser praticadas com a finalidade de formar um elo entre visitante e a necessidade/importância da conservação da natureza.

Somete criar um plano de uso público e/ou de manejo, como qualquer instrumento de planejamento não é o bastante para garantir que as atividades relacionadas à visitação proporcionem ao turista a oportunidade de se sensibilizar para a conservação da natureza, sendo necessária a revisão e atualização deste instrumento, dos funcionários, gestores e da comunidade local envolvida com o turismo na UC.

Pode-se concluir também que o fato do PNMSR estar em processo de criação (2011) torna-se determinante para que estudos futuros sejam desenvolvidos, sendo estes estabelecidos através de planos, programas, projetos e ações determinados o plano de manejo da unidade.

\section{Referências bibliográficas}

BRASIL. Decreto $n^{0} 4.340$, de 22 de agosto de 2002. Regulamenta artigos de lei $n^{0} 9985$, de 18 de julho de 2000, que dispõe sobre o Sistema Nacional de Unidades de Conservação da Natureza. Diário Oficial da União, Brasília, DF, 23 de ago., 2002.

Brasil. LEI $N^{\circ}$ 9.985, de 18 de julho de 2000. Regulamenta o art. 225, $§ \mathbf{1}^{\mathbf{0}}$, incisos I, II, III e VII da Constituição Federal, institui o Sistema Nacional de Unidades de Conservação da Natureza e dá outras providências. Disponível em: < www.planalto.gov.br/ccivil_03/Leis/L9985.htm >. Acesso em: 12 set. 2007.

COSTA, P. C. Unidades de Conservação: matéria-prima do ecoturismo. São Paulo: Aleph, 2007.

DIEGUES, A. C. S. O Mito Moderno da Natureza Intocada. 4. ed. São Paulo: Hucitec, 2004. 
IRVING, M. A.; AZEVEDO, J. Turismo: o desafio da sustentabilidade. São Paulo: Futura, 2002.

KINKER, S. Ecoturismo e conservação da natureza em parques nacionais. Campinas, SP: Ed. Papirus, 2002. (Coleção turismo).

\section{LAMAS, A.S. Inventário da oferta turística de Guarani, MG.}

MINAS GERAIS. Decreto Estadual No. 217241981 de 23 de novembro de 1981. Regulamenta os Parques Estaduais de Minas Gerais.

MILANO, M. S. Unidades de conservação : Conceitos e Princípios de Planejamento e Gestão. Curitiba: Fupef - Fundação de Pesquisas Florestais do Paraná, 1989.

MILANO, M. S. Por quê existem as unidades de conservação? In: Unidades de conservação: atualidades e tendências. Miguel Sereduik Milano (Org.). Curitiba: Fundação O Boticário de Proteção à Natureza, 2000. p. 193-208.

PRIMACK, R. B. e RODRIGUES, E. Biologia da Conservação. Londrina: Editora Planta: 2001.

RODRIGUES, C. G. de O. O uso público nos parques nacionais: a relação entre as esferas pública e privada na apropriação da biodiversidade. Brasília, 2009.

INSTITUTO BRASILEIRO DO MEIO AMBIENTE E RECURSOS NATURAIS

RENOVÁVEIS. Disponível em: 〈 www.ibama.gov.br >. Acesso em: 22 set. 2011.

INSTITUTO CHICO MENDES DE CONSERVAÇÃO DA BIODIVERSIDADE. Disponível em: 〈 $\underline{\text { www.icmbio.gov.br }}$. Acesso em: 18 out. 2011.

INSTITUTO ESTADUAL DE FLORESTAS DE MINAS GERAIS. Disponível em: < Www.ief.mg.gov.br >. Acesso em: 15 set. 2011.

PREFEITURA MUNICIPAL DE GUARANI, MG. Disponível em: < www.guarani.mg.gov.br >. Acesso em: 12 set. 2011. 